\title{
DIMENSÕES DA IDENTIDADE DOCENTE EM ARTE: CONSIDERAÇÕES TEÓRICO-CRÍTICAS SOBRE A FORMAÇÃO INICIAL NO MS
}

\author{
DIMENSIONS OF TEACHING IDENTITY IN ART: \\ THEORETICAL-CRITICAL CONSIDERATIONS \\ ABOUT INITIAL FORMATION IN MS
}

DIMENSIONES DE LA IDENTIDAD DOCENTE EN EL ARTE: CONSIDERACIONES TEÓRICO-CRÍTICAS SOBRE LA FORMACIÓN INICIAL EN MS

ANDRÉ Freire MASTROROCCO ${ }^{\mathrm{I}}$

IsABella Fernanda FerReIrA ${ }^{\mathrm{I}}$

'Universidade Federal do Mato Grosso do Sul (UFMS), Campus do Pantanal/MS, Brasil

Resumo O objetivo desse artigo é identificar e mapear as dimensões da identidade docente em Arte materializadas nos Projetos Políticos Pedagógicos (PPP) dos cursos de formação inicial docente neste campo do saber, na modalidade presencial, em Instituições Públicas de Ensino Superior, no Estado do Mato Grosso do Sul. Trata-se de uma pesquisa documental com abordagem quanti-qualitativa. A metodologia da pesquisa consistiu em: primeiramente, coletar os dados junto às instituições de ensino superior, nas quais obtivemos os Projetos Políticos Pedagógicos; segundamente, analisar esses documentos tendo como base as três dimensões da identidade docente em Arte descritas por Mauren Teuber (2016) e, finalmente, apresentar o panorama obtido, com considerações teórico-críticas sobre os documentos coletados, por meio, das contribuições do pensamento de Theodor W. Adorno e Max Horkheimer sobre formação, semiformação e instrumemtalização da razão. Os resultados de nossas análises indicam possíveis riscos à semiformação quando existe dominância de uma dimensão da identidade docente em Arte em relação às demais. As dimensões da identidade docente em arte analisadas foram: o professor como artista, o professor como docente e o professor como pesquisador. Esperamos que este texto possa contribuir para o surgimento de novas propostas de trabalho científico que possuam como

Comunicações Piracicaba | v. 28 | n. 2 | p. 93-116 | maio-ago. 2021 DOI: http://dx.doi.org/10.15600/2238-121X/comunicacoes.v28n2p93-116 
alvo de suas interrogações à formação inicial do docente em Arte, bem como de mais processos investigativos sobre o professor de Arte.

Palavras-chave: Projeto Político Pedagógico, Teoria Crítica da Sociedade, Curso de Licenciatura, Formação Docente, Arte-educaÇão.

\begin{abstract}
The objective of this article is to identify and map the dimensions of the teaching identity in Art materialized in the Political Pedagogical Projects (PPP) of the initial teacher training courses in this field of knowledge, in the face-to-face modality, in Public Institutions of Higher Education, in the State of Mato Grosso do Sul. This is a documentary research with a quantitative-qualitative approach. The research methodology consisted of: first, collecting data from higher education institutions, from which we obtained the Pedagogical Political Projects; secondly, to analyze these documents based on the three dimensions of the teaching identity in Art described by Mauren Teuber (2016) and, finally, to present the obtained panorama, with theoretical-critical considerations about the collected documents, through the contributions of the thought of Theodor W. Adorno and Max Horkheimer on formation, semi-formation and instrumentalization of reason. The results of our analyzes indicate possible risks to semi-education when there is dominance of one dimension of the teaching identity in Art in relation to the others. The dimensions of the teaching identity in art analyzed were: the teacher as an artist, the teacher as a teacher and the teacher as a researcher. We hope that this text can contribute to the emergence of new proposals for scientific work that have as a target of their questions the initial training of teachers in Art, as well as more investigative processes on the Art teacher.
\end{abstract}

Keywords: Political Pedagogical Project, Critical Theory of Society, Degree Course, Teacher Education, Art Education.

RESUMen El objetivo de este artículo es identificar y mapear las dimensiones de la identidad docente en Arte materializada en los Proyectos Político Pedagógicos (PPP) de los cursos de formación inicial docente en este campo del conocimiento, en la modalidad presencial, en Público. Instituciones de Educación Superior, en el Estado de Mato Grosso do Sul. Se trata de una investigación documental con enfoque cuantitativo-cualitativo. La metodología de investigación consistió en: primero, la recolección de datos de las instituciones de educación superior, de las cuales obtuvimos los Proyectos Políticos Pedagógicos; en segundo lugar, analizar estos documentos a partir de las tres dimensiones de la identidad docente en el Arte descritas por Mauren Teuber (2016) y, finalmente, presentar el panorama obtenido, con consideraciones teórico-críticas sobre los documentos recogidos, a través de los aportes del pensamiento de Theodor W. Adorno y Max Horkheimer sobre formación, semiformación e instrumentalización de la razón. Los resultados de nuestros análisis indican posibles riesgos para la semi-educación cuando hay un predominio de una dimensión de la identidad docente en el Arte en relación con las otras. Las dimensiones de la identidad docente en el arte analizadas fueron: el docente como artista, el docente como docente y el docente como investigador. Esperamos que este texto pueda contribuir al surgimiento 
de nuevas propuestas de trabajo científico que tengan como objetivo de sus interrogantes la formación inicial de docentes en Arte, así como procesos más investigativos sobre el docente de Arte.

Palabras clave: Proyecto pedagógico político, Teoría crítica de la sociedad, LiCENCIATURA, FormaCión DOCENTE, EdUCACIÓN ARTí́sTiCa.

Os questionamentos contemporâneos acerca do ensino de $\mathrm{Arte}^{1}$ assim como sobre a formação docente em Arte no Brasil têm levado os pesquisadores nessa área do saber a pensar, por exemplo, sobre em que bases o docente em Arte está sendo formado o que implica, inexoravelmente, refletir sobre as dimensões da identidade do docente nos cursos de formação inicial docente neste campo do conhecimento, principalmente aqueles que têm como objetivo a formação para a educação formal, ou seja: as licenciaturas em linguagens artísticas (artes visuais, artes cênicas, dança e música).

Outro ponto que cerca o universo da Arte na Educação Básica é o descaso e desvalorização que a disciplina possui no contexto formal escolar. Em muitos locais, sem importar o nível de ensino, este campo do saber está atrelado a práticas de criação descontinuadas e muitas vezes desprovidas de qualquer sentido teórico e metodológico. Outras vezes, a Arte é utilizada como disciplina decoradora de eventos e produtora de lembranças em datas comemorativas, como o dia das mães ou dos pais.

Nas diversidades desse imenso país, existem escolas que dedicam as aulas de arte ao desenho geométrico, a cargo de um professor de matemática. Há escolas rurais onde as aulas de arte são destinadas a trabalhos manuais, ou até mesmo a fazer salada de frutas! [...] Enfrenta-se ainda, por parte de diretores de escolas, alunos e demais professores, a desvalorização da área de arte, uma vez que ou não se conhece, ou se desconsidera o papel que o ensino de arte pode e deve ter na democratização da cultura. (PENNA, 1999, p. 58)

Este cenário decorre, dentre outros fatores, pela ausência de número suficiente de profissionais licenciados em alguma linguagem artística inseridos na educação básica, o que acarreta a designação da disciplina como complementação de carga horária, a docentes formados em outras áreas do conhecimento e que, muitas vezes, sequer possuíam formação complementar que os habilitassem de fato a prática docente em Arte. $\mathrm{O}$ fato é que na primeira década do século XXI, o número de professores formados em alguma linguagem artística era bastante baixo, como hoje ainda é em relação à demanda. De acordo com Sônia Tramujas Vanconcellos (2014) essa escassez de docentes na área tem como causa, dentre outras, um insuficiente número de cursos de Licenciatura em qualquer linguagem artística:

\footnotetext{
1 A terminologia Arte ou Ensino de Arte passa a figurar nos documentos oficiais principalmente após a publicação dos Parâmetros Curriculares Nacionais (PCN - 1996) que tratam da grande área de Arte. Mais que uma mudança na nomenclatura, trata-se de um embate semântico, epistemológico e político, por serem denominações que carregam em si abordagens, encaminhamentos metodológicos e diferentes concepções de conhecimento e de ensino. (Teuber, 2016 p. 25). Desta forma, sempre que nos referirmos a Arte como uma disciplina escolar ou campo do conhecimento, será grafada com inicial maiúscula e no singular.
} 
Dados do Censo Escolar de 2007 apontam que dos professores que ensinam arte, apenas $25,7 \%$ dos anos finais do ensino fundamental e 38,2\% do Ensino Médio têm formação na área. Os demais são formados em pedagogia ou outras áreas. Este quadro é reforçado pelo baixo número de cursos de licenciatura nas diversas linguagens artísticas. Em 2008 existiam no Brasil aproximadamente 120 cursos, sendo que $95 \%$ concentravam-se nas regiões Sul e Sudeste do país. (VASCONCELLOS, 2014; p. 8)

Nesse sentido, a formação inicial para a docência em Arte passa a se configurar como elemento fundamental na mudança do paradigma acima colocado, tanto no que se se refere ao alcance de número suficiente de profissionais para atender a demanda e a legislação atuais quanto no que tange as especificidades da identidade deste docente em seu percurso formativo. Mauren Teuber (2016) estabelece que um dos desafios para a formação docente em Arte no Brasil é o reconhecimento, já durante a licenciatura, de três dimensões que compõem a identidade profissional do professor de Arte e que estão ligadas diretamente a função profissional docente, a ação expressiva enquanto artista e as possibilidades de conduzir e instigar processos investigativos e exploratórios, característicos do universo da pesquisa. De acordo com o pensamento desta autora "o desafio para a formação docente, e para o trabalho dos formadores de professores de Artes Visuais, é o reconhecimento das dimensões que se entrelaçam em torno da docência, da prática artística e da pesquisa" (TEUBER, 2016, p. 92).

Neste sentido, buscamos analisar a formação inicial do professor de Arte em instituições públicas de ensino superior no estado do Mato Grosso do Sul, investigando como as dimensões da identidade docente em Arte descritas por Teuber (2016) se revelam nos Projetos Políticos Pedagógicos ${ }^{2}$ (PPP) dos cursos de Licenciatura em linguagens artísticas, na modalidade presencial, em Instituições Públicas, tendo com enfoque o expresso principalmente no perfil desejado de egresso e nos currículos dos projetos.

Também precisamos nos situar quanto à concepção de educação que possuímos como alicerce neste trabalho. Temos como premissa a ideia de educação advinda da Teoria Crítica da Sociedade. Esta concepção parte do princípio que os moldes muitas vezes utilizados e valorizados pela educação nada mais fazem do que reforçar a dominação imposta pela indústria cultural ao possuírem como objetivo pedagógico a modelagem de pessoas e que os processos educacionais atuais são frutos de uma visão de formação autoritária, levando o educando a ser um objeto reprodutor consciente da realidade de dominação social vigente, afirmando-a cada vez mais.

A seguir, e assumindo o risco, gostaria de apresentar a minha concepção ini-

2 Os PPP's mapeados neste trabalho podem ser encontrados nos links abaixo:

1) Licenciatura em Artes Plásticas - UFMS: https://prograd.ufms.br/files/2017/01/Artes-Visuais-CCHS-c\%C3\%B3d.-36348.pdf

2) Licenciatura em Música - UFMS: https://prograd.ufms.br/files/2017/01/M\%C3\%BAsica-CCHS-c\%C3\%B3d.-59103.pdf

3) Licenciatura em Artes Cênicas - UEMS: http://www.uems.br/graduacao/curso/artes-cenicas-danca-licenciatura-campo-grande/projeto pedagogico

4) Licenciatura em Artes Cênicas - UFGD: http://files.ufgd.edu.br/arquivos/arquivos/78/COGRAD/ PPC\%20ARTES\%20CENICAS\%202017.pdf 
cial de educação. Evidentemente não a assim chamada modelagem de pessoas, porque não temos o direito de modelar pessoas a partir do seu exterior; mas também não a mera transmissão de conhecimentos, cuja característica de coisa morta já foi mais do que destacada, mas a produção de uma consciência verdadeira. Isto seria inclusive da maior importância política; sua ideia, se é permitido dizer assim, é uma exigência política. Isto é: uma democracia com o dever de não apenas funcionar, mas operar conforme seu conceito demanda pessoas emancipadas. Uma democracia efetiva só pode ser imaginada enquanto uma sociedade de quem é emancipado. (ADORNO, 1995, p. 141-142)

Na compreensão dos teóricos críticos que possuem como arcabouço epistemológico as ideias de Adorno, a concepção de educação e ensino se contrapõe a ideia de moldar o sujeito para o sistema de produção capitalista, ou seja, formar "indivíduos para se submeterem passivamente ao processo de competitividade do mercado" (CORREIA, 2016, p. 112), pelo contrário, a formação dos sujeitos deve incidir sobre todo o processo educacional, como um uma construção contínua de esclarecimento mediado pela experiência formativa, ou seja, da ação pedagógica que permita libertar o estudante para além da reprodução do meio social vigente.

O conteúdo da experiência formativa não se esgota na relação formal do conhecimento - das ciências naturais, por exemplo — mas implica uma transformação do sujeito no curso do seu contato transformador com o objeto na realidade. Para isto se exige tempo de mediação e continuidade, em oposição ao imediatismo e fragmentação da racionalidade formal coisificada, da identidade nos termos da indústria cultural. Assim, a experiência formativa pressupõe uma aptidão cuja ausência caracterizaria a atualidade ainda mais do que a própria falta de conteúdo formativo. (ADORNO, 1995, p. 25)

Adorno (1995) ainda destaca o viés político inegável atribuído por ele aos processos formativos. Segundo o autor, os espaços educacionais devem constantemente ser repensados, criticando o seu próprio fazer. Isso posto como cerne da educação, esse repensar seria capaz de limitar ou mesmo impedir que discursos autoritários e padronizantes que conduziram à barbárie, como ocorrido em Auschwitz no século XX, por exemplo, voltem a incidir novamente na sociedade. Nesse caso, a dimensão política no pensamento de Adorno para a educação está atrelada a essa ideia, porque segundo ele "qualquer debate acerca de metas educacionais carece de significado e importância frente a essa meta: que Auschwitz não se repita. Ela foi à barbárie contra a qual se dirige toda a educação" (ADORNO, 1995, p. 119). Nesse sentido, segundo as ideias de Adorno, a formação do indivíduo deve ser emancipatória no sentido em que conduz o sujeito a liberdade de sua própria consciência, contra a barbárie social, e a partir da consciência crítica (emancipada), emancipa também a sociedade como um todo, transformando-a e também ressignificando-a. Desse modo, ao ousarmos afirmar que existe algum objetivo definido na concepção de formação, de acordo com sua teoria, este seria justamente conduzir os indivíduos "a se afirmarem como racionais numa sociedade racional, como livres numa sociedade livre." (ADORNO, 2005, p. 5).

Esse aspecto ambíguo entre racionalidade e liberdade apontado por Adorno sobre a formação emancipatória, nos revela que, segundo o autor, a educação possui inegavelmente 
um caráter paradoxal: se por um lado a emancipação tem em si um forte viés no sentido de tornar-se consciente por meio da crítica contínua, por outro, seria meramente um pensamento inócuo se também não objetivasse de alguma maneira a formação do sujeito para o significado da vida adulta, e isso significa dizer, inexoravelmente, em apropriar-se de regras, conhecimentos e processos altamente racionalizados e instituídos socialmente.

\footnotetext{
De um certo modo, emancipação significa o mesmo que conscientização, racionalidade. Mas a realidade sempre é simultaneamente uma comprovação da realidade, e esta envolve continuamente um movimento de adaptação. A educação seria impotente e ideológica se ignorasse o objetivo de adaptação e não preparasse os homens para se orientarem no mundo. Porem ela seria igualmente questionável se ficasse nisto, produzindo nada além de well adjusted people, pessoas bem ajustadas, em consequência do que a situação existente se impõe precisamente no que tem de pior. Nestes termos, desde o início existe no conceito de educação para a consciência e para a racionalidade uma ambiguidade. Talvez não seja possível supera-la no existente, mas certamente não podemos nos desviar dela. (ADORNO, 1995, p. 143-144)
}

Para que essa ressignificação resultante da ação pedagógica entre a conformação e a crítica aconteça, Theodor W. Adorno ainda reitera que essa relação, inerente ao processo formativo, aconteça de forma mediada dentro do binômio: adaptação versus autonomia, representando, respectivamente a conformação do sujeito às ditas leis sociais vigentes e a capacidade do sujeito em fazer a crítica livre da sociedade, ao mesmo tempo em que se autocritica enquanto indivíduo.

Quando a educação então não possibilita ao sujeito uma real emancipação, podemos compreender que, segundo os preceitos frankfurtianos, existe uma crise na formação, que passa a sobrepor uma dimensão (adaptação ou autonomia) em detrimento a outra, fazendo com que uma delas se torne um modelo único, impositivo e dominante. De acordo com Bandeira e Oliveira (2012) o desenvolvimento do capitalismo monopolista característico dos anos 1900 e o acesso às novas tecnologias criadas nas décadas finais do século XX favoreceram o aparecimento do que chamam de "nova cultura", universo no qual os produtos culturais vão deixando de possuir valor cultural (simbólico) e passam a ser difundidos para a população com mero valor de troca (mercadológico), como simples artefatos de desejo de consumo para adequação ao meio social instituído. A formação neste cenário "passa a ser vista e entendida unicamente como conformação com a realidade, privilegiando apenas o aspecto adaptativo, excluindo a liberdade do sujeito - espírito" (CORREIA, 2016, p. 118-119).

Esse desequilíbrio no binômio formativo proposto por Adorno reverbera na educação na forma de discursos pedagógicos reacionários e autoritários que possuem como substância a sujeição dos sujeitos aos interesses do reprodutivismo social e da unilateralidade cultural, situação em que a própria formação passa a reforçar ainda mais as imposições opressoras do modo de produção capitalista sobre a sociedade. Dessa forma, ao invés da liberdade e criticidade, que emana do processo formativo baseado na experiência emanci-

BANDEIRA, B.; OLIVEIRA, A. Formação cultural e semiformação: contribuições de Theodor Adorno para pensar a educação hoje. Educação, Porto Alegre,v. 35, n. 2, p. 225-232, maio./ago. 2012. 
patória, tem-se a reafirmação do modo monocultural preconizado pela estrutura dominante. Nesse sentido, a educação "acaba por promover seu contrário, ou seja, uma formação regressiva." (BANDEIRA; OLIVEIRA, 2012, p. 229)

Dessa forma, esse processo regressivo que impede o sujeito de ter uma real experiência formativa emancipatória, limitando-o em uma visão mercadológica de cultura, imposta pelo modo de produção capitalista e que ainda explora o indivíduo como objeto de reprodução deste mesmo mundo que o limita, Adorno denomina de semiformação ou semicultura. Para ele "a semiformação é o espírito tomado pelo caráter de fetiche da mercadoria" (ADORNO, 2005, p. 11). "Na semiformação os conteúdos objetivos são coisificados e a própria formação é reificada, ou seja, transformada em mercadoria". (CORREIA, 2016, p. 12)

Acrescentamos que a semiformação não caracteriza uma falta ou ausência de formação. Visto que, o sujeito semiformado passa por todo um processo sistematicamente "educativo", no entanto essa formação é mercantilizada, administrada de acordo com os interesses do capital, fragmentada e com o propósito de acomodar ainda mais o indivíduo em sua condição de sujeição numa sociedade dominada, ou seja, semiformada. "A semiformação constitui o resultado de um processo sistemático de dominação da formação cultural pelos mecanismos político-econômicos dominantes." (BANDEIRA; OLIVEIRA, 2012, p. 230). Os autores ainda asseveram que a pessoa na condição semiformada se reveste de uma "aparência de ser" e demonstra também ter uma determinada superficialidade sobre aquilo que julga saber, sem conseguir, por exemplo, ser capaz de relacionar ideias de forma crítica.

Através de um narcisismo coletivo, compensa a consciência das pessoas de sua impotência social; não importa ser, importa simplesmente parecer ser. O indivíduo semiculto é aquele que demonstra estar sempre bem informado, a par de tudo o que supostamente acontece, porém de uma forma superficial e acrítica, sem nunca conseguir relacionar os fatos entre si de forma a produzir uma opinião crítica sobre os assuntos em questão. (BANDEIRA; OLIVEIRA, 2012, p. 230)

Outro importante teórico crítico, Max Horkheimer realiza análises quanto a uma possível instrumentalização da razão na sociedade moderna. Para isso, Horkheimer (2002) nos situa em relação a essa dimensão instrumentalizada da linguagem que vê, por exemplo, as expressões artísticas como produto de recreação ou entretenimento; desse modo, claro, se enquadram as artes cênicas, a dança, a música e as artes visuais.

Os conceitos foram "aerodinamizados" racionalizados, tornaram-se instrumentos de economia de mão-de-obra. É como se o próprio pensamento tivesse sido reduzido ao nível do processo industrial, submetido a um programa estrito, em suma, tivesse se tornado uma parte e uma parcela da produção. [...] Quanto mais as ideias se tornam automáticas, instrumentalizadas, menos alguém vê nelas pensamentos com um significado próprio. São consideradas como coisas, máquinas. A linguagem tornou-se apenas mais um instrumento no gigantesco aparelho de produção da sociedade moderna. [...] O significado é suplantado pela função ou efeito no mundo das coisas e eventos. [...] A verdade e as idéias foram radicalmente funcionalizadas e a linguagem é considerada como um mero instrumento, seja para estocagem e comunicação dos elementos intelectuais da produção, seja para orientação das massas. (HORKHEIMER, 2002, p. 26-27) 
Transpondo essa premissa para a formação docente em Arte, ao se renderem a essa dimensão instrumentalizada (semiformada), as linguagens artísticas que compõem o universo da Arte na educação formal acabam por tornarem-se mais um instrumento de alienação das massas no contexto do sistema educacional. Essa possível instrumentalização (semiformação) ainda se mostra de maneira mais concreta quando, por exemplo, a formação inicial docente nesta área está baseada em uma cultura massificada, produzida pela indústria cultural em sua ação formativa. Isso terá como consequência, seguindo o projeto intelectual dos teóricos críticos, uma ação pedagógica docente alienante da sociedade e padronizada enquanto mercadoria, porque assim carrega uma funcionalidade de recreação ou divertimento. Ao invés de seu valor cultural, histórico e expressivo, as manifestações artísticas e culturais envolvidas nos processos pedagógicos, inclusive as realizadas no âmbito escolar pelos alunos, passam a ter um valor funcional, reproduzindo a estrutura social dominante vigente cada vez mais.

[...] na exigência de entretenimento e relaxamento, o fim absorveu o reino da falta de finalidade. Mas, na medida em que a pretensão de utilizar a arte se torna total, começa a se delinear um deslocamento na estrutura econômica interna das mercadorias culturais. Pois a utilidade que os homens aguardam da obra de arte na sociedade antagonística é justamente, em larga medida, a existência do inútil, que no entanto é abolido pela subsunção à utilidade. Assimilando-se totalmente à necessidade, a obra de arte defrauda de antemão os homens justamente da liberação do princípio da utilidade, liberação essa que a ela incumbia realizar. O que se poderia chamar de valor de uso na recepção dos bens culturais é substituído pelo valor de troca; ao invés do prazer, o que se busca é assistir e estar informado, o que se quer é conquistar prestígio e não se tornar um conhecedor. O consumidor torna-se a ideologia da indústria da diversão, de cujas instituições não consegue escapar. (ADORNO \& HORKHEIMER, 1985, p. 129)

Seguindo nessa direção de formação pela emancipação do sujeito, podemos dizer que a semiformação ou a instrumentalização, "apesar do esclarecimento da ilustração e da difusão de informações e mesmo por seu intermédio se tornou a forma dominante da consciência contemporânea" (ADORNO apud MAAR, 2003, p. 468). Neste sentido podemos também dizer que a formação inicial do docente em Arte pode conter elementos que possibilitam que o docente egresso de seu percurso formativo, esteja sujeitado à lógica da semiformação.

Uma das maneiras de observarmos este cenário é analisando como se revelam as dimensões da identidade docente contidas nos seguintes Projetos Políticos Pedagógicos: Licenciatura em Artes Cênicas e Dança, na UEMS - Universidade Estadual do Mato Grosso do Sul, campus Campo Grande, Licenciatura em Artes Cênicas, na UFGD - Universidade Federal da Grande Dourados, campus Dourados, Licenciatura em Artes Visuais - Habilitação em Artes Plásticas na UFMS - Universidade Federal do Mato Grosso do Sul, campus Campo Grande e Licenciatura em Música - Habilitação em Educação Musical na UFMS - Universidade Federal do Mato Grosso do Sul, campus Campo Grande. Esses cursos compõem atualmente o rol de opções de formação docente em Arte, em Instituições públicas, na modalidade presencial. 
Passamos então a observar como os Projetos Políticos Pedagógicos em questão vêm contemplando as dimensões da identidade profissional docente em Arte, como colocadas por Mauren Teuber (2016). Para isso, inicialmente precisamos delinear qual é a concepção de docente em Arte proposta pela autora. Segundo ela, a palavra docente já implica, inicialmente, em pensarmos em um profissional altamente qualificado para a prática pedagógica.

\begin{abstract}
Ainda que muitas vezes nos próprios documentos oficiais, o trabalho do professor seja tratado como tarefa, na verdade é um labor constituído por ações didáticas de alta complexidade, que exigem, para além de um conhecimento dos conteúdos a ensinar e de outros elementos didáticos e pedagógicos, uma formação para a solução de problemas epistemológicos que dizem respeito à especificidade dos temas e abordagens de cada disciplina escolar. Para compreender o significado de algumas opções didáticas e colocar essas opções em andamento nos seus planos de ensino, o professor precisa conhecer com profundidade os elementos que sustentam essas opções. (TEUBER, 2016, p. 81-82)
\end{abstract}

Ademais, segundo a autora o professor deve possuir conhecimentos teóricos específicos da disciplina que ministra como regente, para assim conduzir os estudantes a uma gama de atividades investigativas e reflexivas, durante sua ação pedagógica. Essa dimensão tem como alicerce, a formação de um professor que tenha intrinsicamente ligada à sua prática cotidiana em sala de aula o universo da pesquisa.

\begin{abstract}
Nesse sentido, aponta-se para a necessidade do professor construir uma consciência epistemológica relativa à sua área de atuação, ao mesmo tempo em que se constitui como sujeito epistêmico, sujeito sabedor e construtor de conhecimento. Para tanto é necessário se apropriar do método de produção do conhecimento e uma via indicada é a pesquisa porque ela exige do pesquisador uma compreensão das formas de produção, das regras e procedimentos que constituem a epistemologia do conhecimento que deve ensinar (TEUBER, 2016, p. 53)
\end{abstract}

No que concerne à especificidade do professor de Arte, para além dos conhecimentos didático/pedagógicos necessários para o exercício da atividade docente e de conhecimentos específicos sobre Arte existe ainda uma dimensão que está diretamente ligada à sua capacidade de produção artística, ou seja, sua habilidade técnica e criativa diante do universo subjetivo da Arte.

Outro elemento fundamental que decorre dessa problemática está relacionado à condição do professor de Arte ser um especialista atuante na sua área e, assim, ter o domínio do conhecimento do conteúdo artístico. Em tal perspectiva, entende-se que a compreensão do professor acerca da estrutura da disciplina requer ir além dos fatos e conceitos intrínsecos à disciplina, e pressupõe a compreensão dos processos da produção daquele conhecimento específico que será ensinado. Em outras palavras, espera-se que o professor de Arte desenvolva suas atividades profissionais em intrínseca relação com a poética artística.

(TEUBER, 2016, p. 82) 
Seguindo as ideias desta autora, a partir da perspectiva apresentada, a formação do professor de Arte deve ser "pensada e organizada na interseção entre três dimensões que comporiam a sua identidade profissional: o ensino, a pesquisa e as práticas artísticas." (TEUBER, 2016, p. 82). Dessa forma, podemos então dizer que, segundo essa autora, possuímos três dimensões para análise: a primeira considera a aquisição de conhecimentos didáticos pedagógicos como basilar para o profissional da educação (professor-docente). A segunda refere-se aos conhecimentos sobre Arte e a busca por soluções epistemológicas que se referem a temas e conteúdo que serão abordados com os estudantes, ou seja, o professor-pesquisador. A terceira dimensão está diretamente ligada à habilidade técnica e criativa do professor bem como suas experiências com a criação e produção artísticas (professor-artista).

Sendo assim, para a condução do mapeamento das dimensões da identidade docente em Arte, estamos focalizando nos perfis desejados de egresso expressos em cada Projeto Político Pedagógico. Além disso, procuramos nas características dadas nesses perfis elementos que fossem possíveis de serem classificados como sendo mais ligados a uma dimensão ou outra; ou mais de uma simultaneamente, compilando-os em tabelas. Em paralelo também relacionamos os resultados obtidos neste procedimento a observação de cargas horárias das ementas das disciplinas.

Iniciando nossa análise, tomemos inicialmente o Projeto Político Pedagógico do curso de Licenciatura em Artes Visuais da Universidade Federal do mato Grosso do Sul - UFMS. Vejamos o que afirma esse documento acerca do perfil do egresso desejado na proposta formativa:

\subsection{PERFIL DESEJADO DO EGRESSO}

O egresso do Curso de Artes Visuais - Licenciatura, deverá ser um profissional com as seguintes características:

a) Conhecer conceitos dos Fundamentos, Poéticas, Ensino de Arte, em específico de Artes Visuais, para mediação entre teoria e prática na docência;

b) Conhecer, compreender e refletir sobre as abordagens do Ensino de Artes Visuais para elaborar, aplicar, estratégias em diferentes níveis e espaços de ensino e aprendizagem;

c) Conhecer e compreender a estrutura de uma instituição de ensino para colaborar naquele espaço;

d) Ser capaz de identificar e gerir conflitos no espaço escolar;

e) Ser capaz de realizar a leitura sociopolítica dos espaços;

f) Ser um cidadão ativo em sua comunidade (UFMS, 2018 p. 10)

Vejamos ainda como se configuram essas características quando dispostas pela dimensão da identidade docente em Arte: 
Quadro I. Dimensões e características do egresso desejado em Licenciatura em Artes Visuais - UFMS

\begin{tabular}{|c|c|c|}
\hline \multicolumn{3}{|c|}{ Licenciatura em Artes Visuais } \\
\hline \multirow{4}{*}{ UFMS } & Dimensão & Característica \\
\hline & $\begin{array}{l}\text { Professor-Artista } \\
\text { (Voltada a formação técnica } \\
\text { do artista) }\end{array}$ & $\begin{array}{l}\text { a) Conhecer conceitos dos Fundamentos, Poéticas, } \\
\text { Ensino de Arte, em específico de Artes Visuais, para } \\
\text { mediação entre teoria e prática na docência; } \\
\text { b) Ser um cidadão ativo em sua comunidade }\end{array}$ \\
\hline & $\begin{array}{l}\text { Professor-Docente } \\
\text { (Voltada a formação em } \\
\text { educação/pedagógica) }\end{array}$ & $\begin{array}{l}\text { a) Conhecer, compreender e refletir sobre as abordagens } \\
\text { do Ensino de Artes Visuais para elaborar, aplicar, } \\
\text { estratégias em diferentes níveis e espaços de ensino e } \\
\text { aprendizagem; } \\
\text { b) Conhecer conceitos dos Fundamentos, Poéticas, } \\
\text { Ensino de Arte, em específico de Artes Visuais, para } \\
\text { mediação entre teoria e prática na docência; } \\
\text { c) Conhecer e compreender a estrutura de uma } \\
\text { instituição de ensino para colaborar naquele espaço; } \\
\text { d) Ser capaz de identificar e gerir conflitos no espaço } \\
\text { escolar; } \\
\text { e) Ser um cidadão ativo em sua comunidade. }\end{array}$ \\
\hline & $\begin{array}{l}\text { Professor-pesquisador } \\
\begin{array}{l}\text { (Voltada a formação do } \\
\text { pesquisador) }\end{array}\end{array}$ & $\begin{array}{l}\text { a) Ser capaz de realizar a leitura sociopolítica dos } \\
\text { espaços. }\end{array}$ \\
\hline
\end{tabular}

Fonte: PPP de Licenciatura em Artes Visuais da UFMS. Elaborado pelo autor.

Analisando a definição do perfil de egresso podemos observar que a dimensão do professor-artista pode ser identificada na letra "a", quando, por exemplo, cita como caracterís-

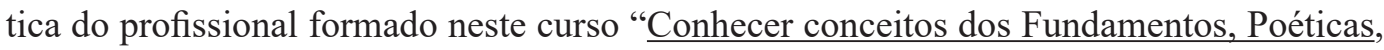
Ensino de Arte, em específico de Artes Visuais, para mediação entre teoria e prática na docência". (UFMS, 2018 P. 10. grifo nosso). No entanto, essa dimensão da formação artística não é tão explicitada no perfil do egresso, quanto expressa na grade curricular, o que se mostra contraditório. Observamos também que a carga horária obrigatória ofertada que contempla essa dimensão da formação do professor-artista atinge o índice de $34,12 \%$, isso corresponde a pouco mais de um terço de toda a carga horária obrigatória na formação do professor de Arte prevista neste PPP. Desse modo, se o percurso formativo contempla toda essa carga horária de formação profissional artística, deveria então considerar de maneira mais ampliada essa dimensão do professor-artista em seu perfil de egresso.

Seguindo nossa análise, percebemos que o perfil de egresso registrado neste documento está intrinsicamente ligado à dimensão do professor-docente. Todas as letras do perfil do egresso deste projeto apontam, de maneira mais ou menos direta, a identidade do professor bem como a do professor de Arte específico da linguagem que trata o projeto, neste caso Artes Visuais. Podemos então assumir que o perfil de egresso expresso neste PPP colabora com o disposto na grade curricular e ementários analisados. Essa afirmação encontra respaldo, por exemplo, quando observamos predominância de carga horária vol- 
tada a formação docente geral ou a formação docente especifica para a linguagem artística. Somadas chegam ao nível de $65,88 \%$, sendo $21,84 \%$ em carga horária de formação em educação ou arte-educação e 44,04\% de carga horária voltada à formação específica em Artes Visuais.

Em outra ponta, ao buscarmos a dimensão do professor-pesquisador, não encontramos menções mais explícitas e podemos pontuar que essa concepção se mostra bastante vaga no PPP. Nesse sentido podemos notar que a formação docente prevista neste projeto não se relaciona muito com a dimensão da pesquisa, enquanto elemento característico da ação pedagógica do profissional egresso deste itinerário.

Passamos então a observar o Projeto Político Pedagógico do curso de Licenciatura em Música, da UFMS - Universidade Federal do Mato Grosso do Sul, para ver como se apresenta no que tange ao perfil do egresso deste curso em relação as dimensões da identidade docente em Arte. Segue abaixo trecho extraído do PPP.

\subsection{PERFIL DESEJADO DO EGRESSO}

O perfil esperado do egresso do Curso de Música - Educação Musical (Licenciatura) é o do educador que demonstre pensamento reflexivo, sensibilidade artística, prática musical consciente, liberdade de experimentação artística e sensibilidade estética através do conhecimento de estilos, repertórios, obras e outras criações musicais, revelando habilidades e aptidões indispensáveis à atuação profissional na sociedade, nas dimensões artísticas, culturais, sociais, científicas e tecnológicas, inerentes à área da Educação Musical.

Além disso, pretende-se formar um profissional que atenda de imediato as principais carências existentes na sociedade do Estado do Mato Grosso do Sul. Nesse sentido, o egresso deverá possuir as seguintes características:

- domínio dos conteúdos e das metodologias a serem ministradas nos diferentes espaços de educação musical;

- conhecimento na área musical: ler e executar partituras, cantar ou tocar instrumento, com razoável habilidade técnica, seja com fins artísticos ou como instrumento musicalizador;

- capacidade de reger grupos musicais vocais e instrumentais;

- conhecimento na área pedagógica: conhecer e pautar sua prática em princípios didáticos, fundamentados nos referenciais teórico-metodológicos da educação musical;

- autonomia e criatividade para as diversas situações pedagógicas, utilizando-se de seus conhecimentos musicais e pedagógicos para atuar de forma transformadora;

- postura crítica e instigadora, buscando através da prática de pesquisa, respostas às questões de sua realidade;

- atuar de forma consciente de seu papel de músico e de educador na sociedade atual, capaz de conjugar as duas atividades com profundidade e objetividade. (UFMS, 2013, p. 10)

Começamos nossa análise enfocando nos dois parágrafos textuais deste perfil de egresso. Logo no início do projeto, o documento é claro quanto a intenção da formação docente, englobando aí a dimensão do professor-docente: "O perfil esperado do egresso do Curso de Música - Educação Musical (Licenciatura) é o do educador [...]” (UFMS, 2013. p. 10 grifo nosso); o que nos indica o adequado direcionamento do projeto por tratar-se de um curso de Licenciatura em Música. O texto também explora de forma bastante robusta a dimensão do professor-artista, destacando para a "sensibilidade artística, prática musical 
consciente, liberdade de experimentação artística e sensibilidade estética através do conhecimento de estilos, repertórios, obras e outras criações musicais, [...]" (UFMS, 2013. p. 10), o que dialoga com a grade curricular e ementários disciplinares que destinam até 34,90\% da carga horária obrigatória a dimensão da formação do artista profissional. A dimensão do professor-pesquisador que, como no projeto analisado anteriormente não apareceu de forma muito clara, se repete aqui; pelo menos nesta parte textual. Podemos destacar como aproximações do universo da pesquisa, os seguintes trechos: "O perfil esperado do egresso do Curso de Música - Educação Musical (Licenciatura) é o do educador que demonstre pensamento reflexivo" (UFMS, 2013 p. 10 grifo nosso), bem como quando cita "aptidões indispensáveis à atuação profissional na sociedade, nas dimensões artísticas, culturais, sociais, científicas e tecnológicas, inerentes à área da Educação Musical." (UFMS, 2013 p. 10 grifo nosso). No entanto, para ampliarmos mais nossa análise no que diz respeito a esse perfil de egresso, especificamente, o professor de música, devemos também observar as características descritas do professor formado sob a lente deste PPP. Para isso dividimos os 07 itens que constam no PPP, de acordo com a dimensão da identidade docente em Arte. Vale ressaltar que algumas características estão ligadas a mais de uma dimensão.

Quadro II. Dimensões e características do egresso desejado em Licenciatura em Artes Visuais - UFMS

\begin{tabular}{|c|c|c|}
\hline \multicolumn{3}{|c|}{ Licenciatura em Música } \\
\hline \multirow{4}{*}{ UFMS } & Dimensão & Característica \\
\hline & $\begin{array}{l}\text { Professor-Artista } \\
\text { (Voltada a formação técnica } \\
\text { do artista) }\end{array}$ & $\begin{array}{l}\text { a) conhecimento na área musical: ler e executar } \\
\text { partituras, cantar ou tocar instrumento, com razoável } \\
\text { habilidade técnica, seja com fins artísticos ou como } \\
\text { instrumento musicalizador; } \\
\text { b) capacidade de reger grupos musicais vocais e } \\
\text { instrumentais; } \\
\text { c) atuar de forma consciente de seu papel de músico e } \\
\text { de educador na sociedade atual, capaz de conjugar as } \\
\text { duas atividades com profundidade e objetividade. }\end{array}$ \\
\hline & $\begin{array}{l}\text { Professor-Docente } \\
\text { (Voltada a formação em } \\
\text { educação/pedagógica) }\end{array}$ & $\begin{array}{l}\text { a) domínio dos conteúdos e das metodologias a serem } \\
\text { ministradas nos diferentes espaços de educação musi- } \\
\text { cal; } \\
\text { b) conhecimento na área pedagógica: conhecer e pautar } \\
\text { sua prática em princípios didáticos, fundamentados } \\
\text { nos referenciais teórico-metodológicos da educação } \\
\text { musical; } \\
\text { c) autonomia e criatividade para as diversas situações } \\
\text { pedagógicas, utilizando-se de seus conhecimentos } \\
\text { musicais e pedagógicos para atuar de forma } \\
\text { transformadora. }\end{array}$ \\
\hline & $\begin{array}{l}\text { Professor-pesquisador } \\
\text { (Voltada a formação do } \\
\text { pesquisador) }\end{array}$ & $\begin{array}{l}\text { a) postura crítica e instigadora, buscando através } \\
\text { da prática de pesquisa, respostas às questões de sua } \\
\text { realidade. }\end{array}$ \\
\hline
\end{tabular}

Fonte: PPP de Licenciatura em Música da UFMS. Elaborado pelo autor. 
Diante deste cenário, podemos então apontar na perspectiva na qual esse Projeto Político Pedagógico, contempla em maior ou menor grau, as três dimensões apontadas por Mauren Teuber. No entanto, percebemos mais uma vez que a dimensão do professor-pesquisador surge de maneira mais discreta, em relação as outras duas dimensões (artista e docente). O currículo do curso segue o mesmo princípio do exposto no perfil do egresso previsto neste PPP, pois apresenta predominância de carga horária voltada a formação técnica do artista e de temas voltados a educação musical, como pudemos observar anteriormente.

Vejamos agora como se configura o PPP do curso de Licenciatura em Artes Cênicas da UFGD - Universidade Federal da Grande Dourados. Este curso em particular, compartilha grande parte da carga horária com o Bacharelado em Artes Cênicas e passa a se diferenciar a partir do $5^{\circ}$ semestre. Essa característica híbrida entre licenciatura e bacharelado aparece também no perfil do egresso exposto neste projeto.

\section{PERFIL DESEJADO DO EGRESSO}

O graduado em Artes Cênicas deverá ser identificado por múltiplas competências e habilidades adquiridas ao longo do Curso, são muitas delas comuns aos dois graus conferidos. A seguir podem ser verificadas essas habilidades/competências discriminadas para cada um dos graus conferidos no curso. (UFGD, 2017, p. 21 grifo nosso)

Essa mesma lógica - de formação híbrida entre licenciatura e bacharelado - ganha ainda mais força quando observamos as características do perfil do egresso das duas modalidades distintas. Vejamos abaixo como estão dispostas no PPP as características tanto do bacharelado quanto da licenciatura da UFGD:

\section{1. Perfil desejado do egresso em bacharelado}

Em consonância com a legislação do Conselho Nacional de Educação, o bacharel do Curso de Artes Cênicas da FACALE/UFGD deve apresentar o perfil de um profissional com formação teórica e prática que:

- demonstre postura de permanente busca de atualização profissional no espaço em que o curso se insere - espaço marcado pela diversidade cultural da região. - tenha uma visão pluralista e postura crítica em relação à área de sua formação. - tenha habilidade de ler, produzir e pôr em prática as diversas linguagens cênicas.

- seja capaz de intervir socialmente, procurando promover, valorizar e difundir as diversas manifestações culturais.

- possua habilidades para atuar nas várias linguagens que integram o campo dos saberes das artes cênicas, como, por exemplo, cenografia, figurino, iluminação.

- seja um profissional crítico, reflexivo e independente, apto a desenvolver o ensino, a pesquisa e a extensão.

- tenha iniciativa de interferir no mercado de trabalho, criando novas possibilidades de atuação intelectual e artística.

- tenha conhecimento da cultura regional e de sua importância na construção/ formação de identidades culturais no Brasil e fronteiras.

- seja capaz de propor e/ou coordenar projetos em Artes Cênicas ou áreas afins no âmbito de instituições de ensino e de outra natureza.

- seja capaz de contribuir, no exercício da profissão, para o desenvolvimento artístico e cultural da região e do país. (UFGD, 2017, p. 21-22, grifo nosso) 
Ainda sobre o perfil desejado do egresso, mas, para a licenciatura, o documento por nós coletado e analisado, pontua as seguintes exigências formativas:

\section{2. Perfil desejado do egresso em licenciatura}

Em consonância com a legislação do Conselho Nacional de Educação, o Licenciado do Curso de Artes Cênicas da FACALE/UFGD deve apresentar o perfil de um profissional com 22 formação teórica e prática que:

- demonstre postura de permanente busca de atualização profissional no espaço em que o curso se insere - espaço marcado pela diversidade cultural da região. - tenha visão pluralista e postura crítica em relação à área de sua formação.

- tenha habilidade de ler, produzir e pôr em prática as diversas linguagens cênicas.

- contribua para o desenvolvimento da educação do país, por meio da arte/ educação, do exercício de práticas pedagógicas, de pesquisa e do fazer teatral.

- seja capaz de intervir socialmente, procurando promover, valorizar e difundir as diversas manifestações culturais por meio da arte/educação.

- possua habilidades para atuar nas várias linguagens que integram o campo dos saberes das Artes Cênicas, como, por exemplo, cenografia, figurino, iluminação.

- seja capaz de dominar e de criar metodologias de ensino adequadas à arte teatral em suas diferentes linguagens.

- seja um profissional crítico, reflexivo e independente, apto a desenvolver o ensino, a pesquisa e a extensão.

- tenha iniciativa de interferir no mercado de trabalho, criando novas possibilidades de atuação intelectual e artística.

- tenha conhecimento da cultura regional local e de sua importância na construção/formação de identidades culturais no Brasil e fronteiras.

- seja capaz de propor e/ou coordenar projetos em Artes Cênicas ou áreas afins no âmbito de instituições de ensino e de outra natureza.

- seja capaz de contribuir, no exercício da profissão, para o desenvolvimento artístico e cultural da região e do país. (UFGD, 2017, p. 21-22, grifo nosso)

Os grifos na citação acima destacam as únicas diferenças entre as características do bacharelado e da licenciatura em Artes Cênicas. Temos nesse momento somente três diferenças que remetem ao ensino das artes cênicas propriamente dito. Sendo assim, unicamente isso que diferencia as características de um bacharel para um licenciado neste PPP. Dessa forma, considerando que o egresso licenciado poderá assumir todas as características do bacharel, podemos inferir que essa formação está bastante ligada a dimensão do professor-artista. No entanto, lendo a grade curricular e ementário do referido projeto, observamos que esse curso apresenta certo equilíbrio na distribuição de carga horária no que concerne a formação artística $(37,23 \%$ da $\mathrm{CH})$ e a formação específica para o ensino das artes cênicas $(40,87 \%$ da $\mathrm{CH})$. Só esse dado já indica um projeto em que predomina a formação docente, entretanto, isso não se reflete ao analisarmos o perfil do egresso, que está diretamente ligado ao perfil do bacharel em Artes Cênicas na forma como está expresso. A percepção acima apontada ganha maior destaque quando separamos as características do perfil do egresso licenciado neste PPP. Conforme segue: 
Quadro III. Dimensões e características do egresso desejado em Licenciatura em Artes Cênicas - UFGD

\begin{tabular}{|c|c|c|}
\hline \multicolumn{3}{|c|}{ Licenciatura em Artes Cênicas } \\
\hline \multirow{4}{*}{ UFGD } & Dimensão & Característica \\
\hline & $\begin{array}{c}\text { Professor-Artista } \\
\text { (Voltada a formação técnica } \\
\text { do artista) }\end{array}$ & $\begin{array}{l}\text { a) demonstre postura de permanente busca de } \\
\text { atualização profissional no espaço em que o curso se } \\
\text { insere - espaço marcado pela diversidade cultural da } \\
\text { região; } \\
\text { b) tenha habilidade de ler, produzir e pôr em prática as } \\
\text { diversas linguagens cênicas; } \\
\text { c) seja capaz de intervir socialmente, procurando } \\
\text { promover, valorizar e difundir as diversas manifestações } \\
\text { culturais por meio da arte/educação; } \\
\text { d) possua habilidades para atuar nas várias linguagens } \\
\text { que integram o campo dos saberes das Artes Cênicas, } \\
\text { como, por exemplo, cenografia, figurino, iluminação; } \\
\text { e) tenha iniciativa de interferir no mercado de trabalho, } \\
\text { criando novas possibilidades de atuação intelectual e } \\
\text { artística; } \\
\text { f) seja capaz de propor e/ou coordenar projetos em } \\
\text { Artes Cênicas ou áreas afins no âmbito de instituições } \\
\text { de ensino e de outra natureza; } \\
\text { g) seja capaz de contribuir, no exercício da profissão, para } \\
\text { o desenvolvimento artístico e cultural da região e do país. }\end{array}$ \\
\hline & $\begin{array}{l}\text { Professor-Docente } \\
\text { (Voltada a formação em } \\
\text { educação/pedagógica) }\end{array}$ & $\begin{array}{l}\text { a) demonstre postura de permanente busca de atuali- } \\
\text { zação profissional no espaço em que o curso se insere } \\
\text { - espaço marcado pela diversidade cultural da região; } \\
\text { b) tenha visão pluralista e postura crítica em relação à } \\
\text { área de sua formação; } \\
\text { c) contribua para o desenvolvimento da educação do } \\
\text { país, por meio da arte/educação, do exercício de práticas } \\
\text { pedagógicas, de pesquisa e do fazer teatral; } \\
\text { d) seja capaz de dominar e de criar metodologias de } \\
\text { ensino adequadas à arte teatral em suas diferentes } \\
\text { linguagens; } \\
\text { e) seja um profissional crítico, reflexivo e independente, } \\
\text { apto a desenvolver o ensino, a pesquisa e a extensão; } \\
\text { f) seja capaz de contribuir, no exercício da profissão, para } \\
\text { o desenvolvimento artístico e cultural da região e do país. }\end{array}$ \\
\hline & $\begin{array}{c}\text { Professor-pesquisador } \\
\begin{array}{c}\text { (Voltada a formação do } \\
\text { pesquisador) }\end{array}\end{array}$ & $\begin{array}{l}\text { a) demonstre postura de permanente busca de } \\
\text { atualização profissional no espaço em que o curso se } \\
\text { insere - espaço marcado pela diversidade cultural da } \\
\text { região; } \\
\text { b) seja um profissional crítico, reflexivo e independente, } \\
\text { apto a desenvolver o ensino, a pesquisa e a extensão; } \\
\text { c) tenha conhecimento da cultura regional local e de } \\
\text { sua importância na construção/formação de identidades } \\
\text { culturais no Brasil e fronteiras. }\end{array}$ \\
\hline
\end{tabular}

Fonte: PPP de Licenciatura em Artes Cênicas da UFGD. Elaborado pelo autor. 
Considerando as características do egresso do projeto deste curso de Licenciatura podemos notar que a maioria dos itens elencados no documento apresenta ligações com a dimensão do professor-artista, reiterando a observação inicial. No entanto, a dimensão do professor-docente também está bastante presente no perfil do egresso, mesmo que se diferenciando minimamente do curso de bacharelado, como observamos acima. Mais uma vez não temos muitas características elencadas no PPP que façam referência à dimensão do professor-pesquisador. A letra "b" é a que indica de forma mais direta essa dimensão, mas de maneira mais geral ao também citar junto o ensino e a extensão. As demais letras que compõem este cenário também se aplicam a outras dimensões.

Ainda se observa, quando procuramos buscar no PPP disciplinas e/ou ementas que possuem ligação direta com conteúdos educacionais como planejamento e avaliação, certo cenário de escassez. Neste projeto existe como carga horária obrigatória uma disciplina chamada "Fundamentos de didática" que adentra em questões educacionais mais gerais de cunho teórico/prático e uma outra intitulada "História da Educação e do Teatro na Educação", que como o nome já diz apresenta um ponto de vista histórico da educação alinhavado ao teatro. Além destas, o currículo apresenta os conteúdos educacionais na disciplina de "Estágio Supervisionado I", da forma como colocamos abaixo:

Estágio Supervisionado I - Sondagem de temas para o desenvolvimento de trabalhos na educação básica e comunidades. Interfaces artísticas nos currículos do ensino fundamental. Contato com práticas existentes: estudo de caso. Estudo e reflexão formativa da relação teoria-prática, universidade-escola-comunidade. Perspectiva histórica da área. Objetivos e Métodos. Planejamento e Construção de projeto de estágio. Sondagem de temas para o desenvolvimento de trabalhos. Prática de estágio de observação, tanto dos processos pedagógicos, quanto da gestão escolar. (UFGD, 2017, p. 38)

Ao nos atentarmos para a ementa desta disciplina, percebemos que ela traz consigo diversos conteúdos ligados a educação como "Objetivos e Métodos" (UFGD, 2017 p. 38) ou mesmo questões ligadas a planejamento e avaliação. Ao analisarmos a bibliografia referente a este componente curricular contida no PPP, notamos que as obras elencadas não possuem muita ligação direta com esses temas, apontando mais para o ensino das Artes Cênicas. Podemos então assumir que, diante do cenário analisado, esse projeto trata quase que exclusivamente da educação como ensino de Artes Cênicas e, talvez, não assuma em sua proposta a dimensão do professor-docente de maneira tão robusta, quanto expresso no perfil do egresso deste Projeto Político Pedagógico. Esse descompasso se expressa também na grade curricular do projeto quando observamos que a carga horária destinada a formação do artista equivale a $37,23 \%$ do total obrigatório e a formação do docente da linguagem artística específica (artes cênicas) chega ao nível de 40,87\%. Somadas chegam ao índice de $78,10 \%$ de toda carga horária obrigatória do projeto. Observamos também que embora o PPP faça referência a questões sobre cultura regional e local e pensamento crítico reflexivo, pouco disso é expresso quando analisamos a grade curricular e ementários e não encontramos nenhuma disciplina que aponte diretamente em uma dessas duas direções.

Passamos então a analisar o perfil do egresso do PPP do curso de Licenciatura em Artes Cênicas da UEMS - Universidade Estadual do Mato Grosso do Sul. Primeiramente 
gostaríamos de destacar que esse projeto possui um tipo de formação híbrida entre o teatro e a dança. "O curso de Artes Cênicas, licenciatura, aborda duas áreas centrais: o teatro e a dança." (UEMS, 2016, p. 8). Essa característica distingue este projeto dos demais analisados porque é o único a apresentar uma formação em duas linguagens artísticas, algo que não é muito usual atualmente. Esta proposta se aproxima do pensamento de Moura (2018) que defende uma formação docente em Arte não concentrada somente em uma linguagem, mas baseada na experiência estética intersemiótica.

O projeto aponta que "coloca-se na contramão de movimentos corporativos que preconizam um ensino especializado e isolado em escolas: Dança, Música, Teatro e Artes Plásticas". A proposta formativa da LI em Arte da UFSB, como uma formação docente na perspectiva polivalente, é, historicamente, combatida no contexto do ensino de Arte brasileiro. [...] Considero que o projeto da LI em Artes da UFSB pensa a formação do/a profissional, que concebe como "educador em Artes" - que opto por chamar Arte/Educador/a -, por uma tendência formativa contemporânea que é a formação de professor/ artista/ pesquisador. (MOURA, 2018, p. 145-146)

Já especificamente considerando o perfil profissional do egresso deste PPP podemos perceber que, embora este seja um projeto de Licenciatura, o texto materializado no corpo do documento nos remete primeiramente a um perfil de artista e secundariamente à profissão docente, visto que esta última deveria ser central em um projeto de Licenciatura.

O Curso de Artes Cênicas, licenciatura tem por finalidade formar artistas docentes aptos para atuarem na Educação Básica, seja na docência da sua área de formação ou na gestão do trabalho educativo. Além da atuação na educação formal, o Curso preparará o profissional para o exercício do pensamento reflexivo e da sensibilidade artística, desenvolvendo capacidades para construir novas formas de expressão e de linguagem corporal, novos valores, significados e sentidos. Visa, portanto, oferecer formação artística e humanística, para que o profissional egresso reconheça seu papel de agente cultural, artístico, social e político. Pressupõe, também, que esse profissional desenvolva competência artística para a aplicação pedagógica desses conhecimentos na sua atuação como docente, na Educação Básica, como pesquisador capaz de desenvolver a arte, a consciência e o estudo dos costumes, das crenças e das tradições culturais brasileiras em constante diálogo com outras culturas. (UEMS, 2016, p. 11 grifo nosso)

Os grifos apontam para um perfil de egresso primeiramente ligado ao artista, no entanto, não podemos deixar de dizer que tanto a dimensão do professor-docente quanto a do professor-pesquisador também aparecem. Esta última de forma bastante discreta, como também observada nos outros projetos analisados. Mas vejamos também como classificamos as características encontradas no perfil de egresso em relação às dimensões: 
Quadro IV. Dimensões e características do egresso desejado em Licenciatura em Artes Cênicas - UEMS

\begin{tabular}{|c|c|c|}
\hline \multicolumn{3}{|c|}{ Licenciatura em Artes Cênicas } \\
\hline \multirow{4}{*}{ UEMS } & Dimensão & Característica \\
\hline & $\begin{array}{c}\text { Professor-Artista } \\
\text { (Voltada a formação técnica } \\
\text { do artista) }\end{array}$ & $\begin{array}{l}\text { a) Competência para comunicar-se e expressar-se } \\
\text { artisticamente, com criatividade respondendo às } \\
\text { exigências especificas de sua área de atuação, na } \\
\text { condição de professor e pesquisador; }\end{array}$ \\
\hline & $\begin{array}{l}\text { Professor-Docente } \\
\text { (Voltada a formação em } \\
\text { educação/pedagógica) }\end{array}$ & $\begin{array}{l}\text { a) Competência para comunicar-se e expressar-se } \\
\text { artisticamente, com criatividade respondendo às } \\
\text { exigências especificas de sua área de atuação, na } \\
\text { condição de professor e pesquisador; } \\
\text { b) Habilidade para inter-relacionar os conteúdos } \\
\text { intelectuais e sensíveis necessários à formação de } \\
\text { cidadãos com princípios artísticos e humanistas, a fim } \\
\text { de promover uma transformação e evolução do meio } \\
\text { sociocultural em que atua; } \\
\text { c) Capacidade de contribuir para o desenvolvimento } \\
\text { da arte e cultura nacional no exercício da produção da } \\
\text { pesquisa e da crítica, bem como do ensino. }\end{array}$ \\
\hline & $\begin{array}{l}\text { Professor-pesquisador } \\
\begin{array}{l}\text { Voltada a formação do } \\
\text { pesquisador) }\end{array}\end{array}$ & $\begin{array}{l}\text { a) Competência para comunicar-se e expressar-se } \\
\text { artisticamente, com criatividade respondendo às } \\
\text { exigências especificas de sua área de atuação, na } \\
\text { condição de professor e pesquisador; } \\
\text { b) Capacidade de contribuir para o desenvolvimento } \\
\text { da arte e cultura nacional no exercício da produção da } \\
\text { pesquisa e da crítica, bem como do ensino. }\end{array}$ \\
\hline
\end{tabular}

Fonte: PPP de Licenciatura em Artes Cênicas da UEMS. Elaborado pelo autor.

Analisando esta tabela podemos observar que a dimensão do artista é a menos contemplada nas características do egresso desta proposta, embora o projeto destaque para a formação do artista-professor. Todavia, quando também comparados a grade curricular, podemos ver que a realidade de formação com caráter mais técnico do artista, é a que se torna mais evidente, revelando uma contradição. De acordo com nossa análise, este PPP possui o maior percentual de maior carga horária destinada a formação do artista, com índice de $38,95 \%$, ao passo que a carga horária de formação mais ligada a educação possui índice de $27,37 \%$, indicando uma formação mais ligada aos aspectos técnicos do artista. No entanto, compulsando a tabela acima, percebemos que a dimensão do professor-docente é a que possui o maior número de características do perfil do egresso.

Por outro lado, podemos também constatar que, a partir de nossa análise sobre este Projeto Político Pedagógico, esta proposta é a que apresenta maior equilíbrio entre as dimensões quando observamos a carga horária obrigatória, o que indica certo descompasso entre o disposto como perfil do egresso e a grade curricular.

Em suma, podemos dizer que existem duas questões centrais, que emergiram nos casos tratados neste trabalho. A primeira delas refere-se ao momento que o Projeto Políti- 
co Pedagógico contempla em demasia a dimensão do professor-artista em detrimento de outras dimensões. Neste cenário, primeiramente o projeto tende a desvirtuar o objetivo principal do curso, que no caso é a formação docente. Não menos importante é que num curso de licenciatura, a formação técnica do artista representa a apropriação de uma razão instrumental, ou seja, uma forma também de adaptação do sujeito a um conhecimento já presente, como são as técnicas de aprendizagem e aprimoramento de práticas das linguagens artísticas. Quando dominante na formação inicial do professor, podemos dizer que existe um risco que esta proposta, quando aplicada, se torne mais um mecanismo totalitário de instrumentalização da razão.

Tendo cedido em sua autonomia, a razão tornou-se um instrumento. [...] A razão tornou-se algo inteiramente aproveitado no processo social. Seu valor operacional, seu papel no domínio dos homens e da natureza tornou-se o único critério para avalia-la. [...] Quanto mais as idéias se tornam automáticas, instrumentalizadas, menos alguém vê nelas pensamentos com um significado próprio. São consideradas como coisas, máquinas. A linguagem tornou-se apenas mais um instrumento no gigantesco aparelho de produção da sociedade moderna. [...] O significado é suplantado pela função ou efeito no mundo das coisas e eventos. [...] De acordo com isso, a busca da verdade, sob controle social é cerceada. (HORKHEIMER, 2002, p. 26-27)

É importante salientar que os pesquisadores frankfurtianos não refutam a razão instrumental. Em suas perspectivas, a razão emancipatória e razão instrumental aliam-se para o esclarecimento do sujeito no sentido de sua emancipação, isto é, para o exercício da consciência livre. O risco a semiformação envolve a dominância da razão instrumental nos processos formativos, entretanto, não há como negar que a razão instrumental é parte da experiência formativa.

Em nenhum momento Adorno e Horkheimer (1947) defendem que não deva existir a razão instrumental. Muito pelo contrário, pois ela é extremamente importante para as relações sociais desse sujeito e faz parte da formação. Contudo, ela não deve ser unilateral, totalitária. Pois se existir apenas ela, temos o processo de coisificação. [...] É evidente que a educação também tem que cuidar da formação instrumental, dando condições ao sujeito de se adaptar socialmente, respeitando as convenções sociais, relacionando-se com as diferentes culturas e nacionalidades. (MONTEIRO, 2016, p. 63)

O outro ponto importante que incide como resultado de nossa análise sobre as dimensões da identidade docente em Arte recai sobre a dimensão do professor-pesquisador, que é pouco explorada em todos os projetos analisados. Isso pode revelar que o universo dos processos investigativos se apresenta ainda de forma insatisfatória na formação do professor de Arte para Educação Básica. A falta desta dimensão no projeto pode indicar uma ausência de contraditório durante a formação inicial, e isso poderá instrumentalizar a formação deste professor, comprometendo severamente a possibilidade de experiência durante a prática educacional, semoformando-o. 
A diferença entre pensamento e ação é anulada. Assim, todo pensamento é considerado como um ato; toda reflexão é uma tese; e toda tese uma divisa ou um lema. Todo mundo é interpelado pelo que diz ou pelo que não diz. Tudo e todo mundo é classificado e rotulado. Assim que um pensamento ou palavra se torna um instrumento, podemos nos dispensar de "pensar" realmente isso, isto é, de examinar detidamente os atos lógicos envolvidos na formulação verbal deste pensamento ou palavra. [...] Tal mecanização é na verdade essencial à expansão da indústria; mas se isso se torna a marca característica das mentalidades, se a própria razão é instrumentalizada, tudo isso conduz a uma espécie de materialidade e cegueira, torna-se um fetiche, uma entidade mágica que é aceita ao invés de ser intelectualmente aprendida. [...] Quanto mais emasculado se torna o conceito de razão, mais facilmente se presta à manipulação ideológica e a propagação das mais clamorosas mentiras (HORKHEIMER, 2002, p. 28-29)

A ausência do pensamento crítico na formação docente não favorece a uma educação emancipatória, pelo contrário, oferece um grande risco a semiformação à medida que possibilita ao educando somente uma adaptação, uma conformação ao que já é dado pela sociedade, ou seja, lhe permite conhecer somente a razão instrumental, eliminando a possibilidade da experiência formativa. "Tal instrumentalização da razão encadeia em si a instrumentalização de quaisquer outras manifestações sociais provenientes do pensamento e da criação humana, incluindo, a Arte." (CASTRO, 2018, p. 57).

Dessa forma, a instrumentalização da formação docente em Arte, refletirá na posterior prática de ensino do egresso, minimizando as práticas investigativas e exploratórias. Compreendemos que a pesquisa é o momento onde os questionamentos emergem e devem ser confrontados. É quando crítica emerge, onde se pratica a autonomia, ou seja, a razão emancipatória. "A crítica para Adorno é a aceitação da contradição e o trabalho permanente da negatividade, presente em qualquer processo de conhecimento". (FREITAG, 2004, p. 51).

Ainda salientamos de acordo com Maar (2003), que a educação precisa corresponder a um verdadeiro questionamento da semiformação, de forma a nos revelar sempre o contraditório, colocando em questão a sociedade como paradigma dominante, ao mesmo tempo em que se auto-critica enquanto indivíduo inserido na própria sociedade e suas relações sociais.

A educação, para ser efetiva, é crítica da semiformação real, resistência na sociedade material presente aos limites que nesta se impõem à vida no "plano" de sua produção efetiva. A emancipação é elemento central da educação, mas, para ser real e efetiva, há que ser tematizada na heteronomia. [...] A contradição real objetiva aponta imanentemente para além de si, por meio da possibilidade de uma negação determinada - não abstrata - da ordem vigente. A "consciência" faz o papel de objetivação da contradição, por ser inversora na medida em que adequa. (MAAR, 2003, p. 473)

Destacamos também que os projetos analisados vêm contemplando as três dimensões da identidade docente em Arte. No entanto, podemos observar que as dimensões do professor-artista e professor-docente vem exercendo maior predominância nos respectivos Projetos Políticos Pedagógicos, em relação a dimensão do professor-pesquisador. Isso pode estar trazendo riscos inerentes a semiformação, uma vez que, dentro desta perspectiva, o bi- 
nômio autonomia versus adaptação se mostra em desequilíbrio. Essa formação instrumentalizada, semiformada, acabará por impactar severamente a prática pedagógica do egresso, tornando-o, sujeito da instrumentalização (semiformação) dos seus educandos à medida que a crítica estará suplantada em função do pragmatismo da adaptação aos processos de sujeição ao mundo dominante vigente.

Em nossa análise constatamos que, embora a formação docente nesta área do saber esteja ainda absorvendo as recentes mudanças no ensino desta área e que os PPPs analisados contemplam as três dimensões da identidade docente em Arte descritas por Mauren Teuber (professor-artista, professor-docente, professor-pesquisador), existem algumas questões que podem causar desequilíbrio na estreita relação entre autonomia e adaptação e que, desse modo, devemos estar atentos. O primeiro deles se refere a uma predominância de formação centrada na dimensão artística, que privilegia a formação do artista em detrimento a formação pedagógica. A segunda questão é uma baixa importância dada a dimensão do professor-pesquisador em todos os projetos analisados, isso pode representar um sério risco a semiformação (instrumentalização), uma vez que a instância do contraditório, da crítica permanente inerente a dimensão da pesquisa fica submetida a lógica do adestramento técnico ou da mera ideologização do pensamento, quando dominada pelas outras dimensões. Esses riscos devem continuar a serem investigados no sentido de sempre evitar que discursos totalitários e/ou autoritários se concretizem na formação docente.

Por fim, destacamos a importância da realização de estudos posteriores a este que investiguem como os aspectos levantados nesta pesquisa estão adentrando no cotidiano da formação docente em Arte. Nesse sentido, as pesquisas de campo e os estudos de caso podem contribuir ainda mais para ampliar os questionamentos acerca da formação inicial docente em Arte, possibilitando a formação de um docente emancipado, capaz de construir processos pedagógicos em Arte que estejam compromissados com uma educação emancipatória e livre do indivíduo.

\section{REFERÊNCIAS}

ADORNO. T. Educação e emancipação. Trad. de Wolfgang Leo Maar. Rio de Janeiro: Paz e Terra, 1995.

ADORNO. T. Teoria da semicultura. Revista Primeira Versão. Porto Velho, v. 13, n.191, mai/ago, 2005.

ADORNO, T.; HORKHEIMER, M. Dialética do esclarecimento: fragmentos filosóficos. Rio de Janeiro: Jorge Zahar Editor Ltda. 1985.

BANDEIRA, B.; OLIVEIRA, A. Formação cultural e semiformação: contribuições de Theodor Adorno para pensar a educação hoje. Revista Educação, Porto Alegre,v. 35, n. 2, p. 225-232, maio. /ago. 2012. 
CASTRO, L. OS OLHARES DE PROFESSORAS DE ARTE DA REDE ESTADUAL DE ENSINO DE UMA CIDADE DO INTERIOR DE MATO GROSSO DO SUL SOBRE O TEATRO NA ESCOLA: UMA ANÁLISE TEÓRICO-CRÍTICA. 2018. 200 p. Programa de Pós-Graduação com área de concentração em Educação Social. (Dissertação de Mestrado) - UFMS, Corumbá.

CORREIA, F. THEODOR ADORNO E O PROBLEMA DA (SEMI)FORMAÇÃO. Revista Kínesis, Santa Maria, n 16, Vol. VIII, p.110-126, jul. 2016.

FREITAG, B. A teoria crítica ontem e hoje. São Paulo: Brasiliense, 1990.

HORKHEIMER, M. Eclipse da razão. São Paulo: Centauro, 2002.

MAAR, W. ADORNO, SEMIFORMAÇÃO E EDUCAÇÃO. Educação e Sociedade. Campinas, n. 83, v. 24, p. 459-476, ago, 2003.

MONTEIRO, G. A CONCEPÇÃO DE EDUCAÇÃO MUSICAL NA LEI 11.769/08: UMA REFLEXÃO TEÓRICO-CRÍTICA. 2016. 132 p. Programa de Pós-Graduação com área de concentração em Educação Social. (Dissertação de Mestrado) - UFMS, Corumbá.

MOURA, E. DE/COLONIALIDADE DA FORMAÇÃO DOCENTE EM ARTE NA AMÉRICA LATINA (BRASIL/COLÔMBIA). Tese (Doutorado) - UFMG, 2018.

PENNA, M. Ensino de Arte: um momento de transição. Pro-Posições, Campinas, n³, v. 10, p. 57-66, nov. 1999.

TEUBER, M. Relações entre ensino, práticas artísticas e pesquisa: questões para a formação de professores de artes visuais In: Vellozo, M; Stecz, S. (Orgs.) Criação, ensino e produção de conhecimento em artes: artes visuais, cinema, dança e teatro. Campo Mourão: Fecilcam, 2016. p. 81-102.

UEMS - Universidade Estadual de Mato Grosso do Sul. Projeto Político Pedagógico do Curso de Artes Cênicas Licenciatura. 2016. Disponível em: http://www.uems.br/graduacao/curso/artes-cenicas-danca-licenciatura-campo-grande/projeto pedagogico Acesso em 01 out. 2019

UFGD - Universidade Federal da Grande Dourados. Projeto Político Pedagógico do Curso de Graduação em Artes Cênicas - Licenciatura e Bacharelado. 2017. Disponível em: http://files.ufgd.edu.br/arquivos/arquivos/78/COGRAD/PPC\%20ARTES\%20 CENICAS\%202017.pdf Acesso em 01 out. 2019

UFMS - Universidade Federal do Mato Grosso do Sul. Projeto Político Pedagógico do Curso de Licenciatura em Artes Plásticas. 2018. Disponível em: https://prograd.ufms. br/files/2017/01/Artes-Visuais-CCHS-c\%C3\%B3d.-36348.pdf Acesso em 01 out. 2019 
UFMS - Universidade Federal do Mato Grosso do Sul. Projeto Político Pedagógico do Curso de Licenciatura em Música. 2018. Disponível em: https://prograd.ufms.br/files/2017/01/M\%C3\%BAsica-CCHS-c\%C3\%B3d.-59103.pdf Acesso em 01 out. 2019

VASCONCELOS, S. AS POLÍTICAS DE FORMAÇÃO DE PROFESSORES E AS REPERCUSSÕES NA DOCÊNCIA EM ARTE In: Anais da 35a Reunião Nacional da ANPEd, Porto de Galinhas, 2012. Disponível em: http://35reuniao.anped.org.br/images/ stories/trabalhos/GT24\%20Trabalhos/GT24-2262 int.pdf Acesso em: 03 jul. 2019

\section{DAdos dos AUTORES}

\section{André Freire Mastrorocco}

Mestre em Educação pela Universidade Federal do Mato Grosso do Sul (UFMS), Campus do Pantanal/PPGE. Licenciado em Artes Cênicas pela Universidade Federal de Ouro Preto (UFOP). Professor efetivo no Instituto Federal do Rio Grande do Norte.

\section{ISABELla Fernanda FERREIRA}

Doutora em Educação pela Universidade Estadual Paulista "Júlio de Mesquita Filho" (UNESP), Araraquara/SP. Mestre em Educação pela UNESP, Araraquara/SP. Pedagoga pela Universidade Federal de São Carlos (UFSCar), São Carlos/SP. Docente Permanente do Programa de Pós-graduação em Educação da UFMS/CPAN. bella.fernandaferreira@ gmail.com

Submetido em: 12-08-2020

Aceito em: 08-08-2021 